\title{
Cavum Septum Pellucidum in the General Pediatric Population and Its Relation to Surrounding Brain Structure Volumes, Cognitive Function, and Emotional or Behavioral Problems
}

(D) M.H.G. Dremmen, (D).H. Bouhuis, (D).M.E. Blanken, (D) R.L. Muetzel, (D) M.W. Vernooij, (DH.E. Marroun, (D) V.W.V. Jaddoe,

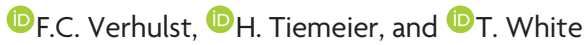

\begin{abstract}
BACKGROUND AND PURPOSE: The cavum septum pellucidum, a cavity filled with CSF, is localized between the 2 lateral ventricles of the brain. The cavum is present in all neonates, but it typically closes within 5 months after birth. In some cases, this closure does not occur and a persistent or enlarged cavum septum pellucidum has been linked, in some studies, to psychiatric disorders. However, the clinical relevance in the general population is unknown. In this study, we examined the relationship between the cavum septum pellucidum and volumes of brain structures, cognitive function, and emotional and behavioral problems in children.
\end{abstract}

MATERIALS AND METHODS: This study was embedded in the Generation R Study, a prospective cohort in Rotterdam, the Netherlands. MR imaging studies of 1070 children, 6-10 years of age, were systematically evaluated for the presence and length of a persistent cavum septum pellucidum. An enlarged cavum septum pellucidum was defined as a cavum length of $\geq 6 \mathrm{~mm}$. Groups without, with persistent, and with enlarged cavum septi pellucidi were compared for brain structure volumes, nonverbal intelligence, and emotional and behavioral problems.

RESULTS: The prevalence of cavum septi pellucidi in our sample was $4.6 \%$. Children with an enlarged cavum septum pellucidum had a larger corpus callosum, greater thalamic and total white matter-to-total brain volume ratio, and smaller lateral ventricle volumes. We did not find a relationship between cavum septi pellucidi and cognitive function or emotional and behavioral problems.

CONCLUSIONS: The cavum septum pellucidum is a normal structural brain variation without clinical implications in this population-based sample of school-aged children.

ABBREVIATIONS: $\mathrm{CBCL}=$ Child Behavior Checklist; $\mathrm{CSP}=$ cavum septum pellucidum; $\mathrm{IQ}=$ intelligence quotient; $\mathrm{M}=$ marginal mean; $\rho_{\mathrm{s}}=\mathrm{Spearman}$ partial correlation; $\mathrm{SE}=$ standard error

$\mathrm{T}$ he septum pellucidum is a thin plate consisting of 2 fused laminae or septa located between the lateral ventricles of the brain. At birth, these 2 septa are separated and form the lateral walls of a cavity filled with CSF, the cavum septum pellucidum (CSP). The 2 septa of the cavum typically fuse into a single septum pellucidum within 5 months after birth, likely due to growth of

Received August 29, 2018; accepted after revision December 1.

From the Departments of Radiology (M.H.G.D., R.H.B., M.W.V., T.W.), Epidemiology (R.L.M., M.W.V., V.W.V.J.), and Pediatrics (V.W.V.J.), Erasmus Medical Center, Rotterdam, the Netherlands; Department of Child and Adolescent Psychiatry (L.M.E.B., R.L.M., H.E.M., F.C.V., H.T., T.W.) and Generation R Study Group (L.M.E.B., R.L.M., H.E.M.), Erasmus Medical Center-Sophia, Rotterdam, the Netherlands; Department of Clinical Medicine (F.C.V.), University of Copenhagen, Copenhagen, Denmark; and Harvard School of Public Health (H.T.), Boston, Massachusetts.

Marjolein H.G. Dremmen and Roos H. Bouhuis contributed equally to this work.

This study was financially supported through Netherlands Organization for Health Research and Development TOP project No. 91211021. The general design of the Generation R Study is made possible by financial support from the Erasmus Medical Center, Rotterdam; the Erasmus University Rotterdam; the Netherlands Organization for Health Research and Development; and the Netherlands Organization for Scientific Research, the Ministry of Health, Welfare and Sport. the surrounding brain structures. ${ }^{1-3}$ However, in some cases, the septa do not fuse and form the persistent cavum. A persistent CSP with a cavum length of $<5 \mathrm{~mm}$ is common in a large proportion of healthy subjects, with prevalence rates of up to $30 \%$ in the adult population, ${ }^{1,4}$ and is therefore considered a normal variant. In general, the size of a normal-variant septum is estimated at approximately $1-4 \mathrm{~mm} .{ }^{1,5}$ There is no clear cutoff value to define enlargement of the CSP, but many previous studies used a common cutoff of $\geq 6 \mathrm{~mm}$.,3,5-16

In patients with schizophrenia and an enlarged CSP, smaller amygdala volumes and smaller left posterior parahippocampal gyrus volumes compared with patients without CSP were found. ${ }^{12}$ Other

Please address correspondence to Marjolein Dremmen, MD, Erasmus Medical Center-Sophia, Department of Radiology, Room Sb-1654, PO Box 2060, 3000 CB Rotterdam, the Netherlands; e-mail: m.dremmen@erasmusmc.nl

- Indicates open access to non-subscribers at www.ajnr.org

三 Indicates article with supplemental on-line tables.

Indicates article with supplemental on-line photos.

http://dx.doi.org/10.3174/ajnr.A5939 
studies did not find a relation to global or specific brain structure volumes. ${ }^{7,9,13,17}$ However, because the postnatal closure of the CSP is presumed to be dependent on growing brain structures, ${ }^{2,3}$ we would expect the brain regions in direct or close contact with the septum pellucidum to be smaller in subjects with enlarged CSPs.

Because an enlarged CSP is considered a neurodevelopmental anomaly, it has been postulated as a potential marker for psychiatric disorders that have neurodevelopmental origins. Indeed, an enlarged CSP has been evaluated in a broad range of psychiatric adult populations, typically by measuring the anterior-to-posterior CSP length on MR imaging studies, but with mixed results. Some studies have shown significantly higher rates of enlarged CSPs in adult patients with schizophrenia, ${ }^{5,9,18}$ schizophrenia spectrum disorder, ${ }^{18}$ bipolar disorder, ${ }^{11}$ and disruptive behavior disorder ${ }^{19}$ and opiate-dependent subjects. ${ }^{16}$ However, other studies did not find higher rates of enlarged CSPs in schizophrenia, ${ }^{2,6,10,12,20}$ bipolar disorder, ${ }^{21}$ and other psychiatric disorders, including attention deficit/hyperactivity disorder, ${ }^{22}$ borderline personality disorder, ${ }^{13}$ depression, ${ }^{13}$ or obsessive-compulsive disorder. ${ }^{14}$

The relationship between CSP and cognition is even less clear. Nopoulos et $\mathrm{al}^{23}$ found a negative correlation between cavum length and the intelligence quotient (IQ) in patients with schizophrenia and an enlarged CSP; however, they did not show this relationship between an enlarged CSP and cognition in the control group. On the other hand, another study has found that a larger proportion of subjects evaluated for mental retardation also had an enlarged CSP. ${ }^{24}$ In addition, an enlarged CSP has been found in children with syndromes that include cognitive impairments such as fetal alcohol syndrome ${ }^{25}$ or Apert syndrome. ${ }^{26}$ These studies may suggest that a relationship exists between an enlarged CSP and cognitive function that extends to the general population.

The heterogeneity in different cutoffs used to define the presence of an enlarged CSP could contribute to some of the mixed findings. The presence of an enlarged CSP, according to the $\geq 6$-mm cutoff varied from $0 \%$ to $19.5 \%$ in patients and from $0 \%$ to $14.7 \%$ in controls. ${ }^{2,3,6-16}$ Because control groups for clinical studies do not always reflect the general population, the prevalence of an enlarged CSP in the general pediatric population is unknown. Thus, the goal of this study was to determine the prevalence of a CSP in the general pediatric population and to examine the relationship between the size of a CSP and brain structure volumes, nonverbal intelligence (as a proxy for cognitive function), and emotional or behavioral problems in children.

Given the previously reported link between an enlarged CSP and behavioral or emotional disorders, ${ }^{11,15,19}$ we hypothesized that a relationship between the size of a CSP and behavioral problems and cognitive performance would be present in a population-based sample of children.

\section{MATERIALS AND METHODS Participants}

The current study was embedded in the longitudinal populationbased Generation R Study. An overview of the Generation R Study design is published elsewhere. ${ }^{27,28}$ Briefly, the Generation R Study is a prospective birth cohort study that started in Rotterdam between 2002 and 2006. After informed consent was obtained, a total of 9778 pregnant women were included. Information on the demographic characteristics included educational levels of the mother. Multiple measurements were collected during pregnancy (eg, maternal alcohol use and smoking behavior). ${ }^{29}$ A neuroimaging substudy of children 6-9 years of age was initiated in 2009 and involved 1070 children. ${ }^{28}$ Exclusion criteria were general contraindications for MR imaging examination (ie, pacemaker, ferrous metal implants), severe motor or sensory disorders (deafness or blindness), neurologic disorders (ie, seizures or tuberous sclerosis), moderateto-severe head injuries with loss of consciousness, and claustrophobia. Informed consent was obtained from the parents before participation. The study was approved by the Medical Ethics Committee at the Erasmus Medical Center-Sophia, Rotterdam. ${ }^{28}$

\section{MR Imaging Acquisition}

Children were familiarized with the MR imaging scanners using a mock scanning procedure. ${ }^{28} \mathrm{MR}$ images were acquired on a 3T scanner (Discovery MR750; GE Healthcare, Milwaukee, Wisconsin) using an 8-channel head coil for signal reception. Following a 3-plane localizing and coil-intensity calibration scan, a high-resolution T1-weighted inversion recovery fast-spoiled gradient-recalled sequence was obtained with the following parameters: $\mathrm{TR}=10.3 \mathrm{~ms}, \mathrm{TE}=4.2 \mathrm{~ms}$, TI $=350 \mathrm{~ms}$, NEX $=1$, flip angle $=$ $16^{\circ}$, readout bandwidth $=20.8 \mathrm{kHz}$, matrix $=256 \times 256$. The total scan time for the T1 was 5 minutes 40 seconds. ${ }^{28}$ The MR images underwent a 6-parameter affine transformation into a study-specific template at $1 \times 1 \times 1 \mathrm{~mm}$ isotropic resolution. ${ }^{30}$

\section{CSP Assessment}

The CSP was assessed in a standardized manner by a single trained neuroradiologist, blinded to subject information. Anatomic boundaries for the CSP were as follows: the genu of the corpus callosum defined the anterior boundary, the body of the corpus callosum defined the superior boundary, the rostrum of the corpus callosum and the anterior commissure defined the inferior boundary, and the anterior limb and pillars of the fornix defined the posterior boundary. On-line Fig 1 illustrates the anterior and posterior boundaries of the CSP in the sagittal plane. Similar to other studies, ${ }^{5-9,12,13,15,19,20,22,23}$ the anterior-to-posterior length of the CSP was measured by counting the number of coronal 1 -mm slices on which a cavum was visible. A cavum was labeled as enlarged when its length was $\geq 6$ slices (ie, $\geq 6 \mathrm{~mm}$ ). ${ }^{2,3,6-16} \mathrm{Ab}$ sence of a CSP was labeled "no CSP." A cavum of $<6 \mathrm{~mm}$ in length was categorized as a normal-variant CSP. Figure 1 illustrates the presence of an enlarged CSP. Intrarater reliability was based on 50 repeat ratings and was found to be high (test-retest reliability, Cronbach $\alpha=0.96$ ). Scans that were of insufficient quality to determine the existence or length of a CSP were excluded from the analyses $(12.5 \%, n=134)$. The insufficient scan quality was mainly due to movement artifacts, which are a wellknown problem when performing MR imaging studies in unsedated children at a young age.

\section{Global and Regional Brain Structures}

Volumes of global and regional brain structures were measured using FreeSurfer image analysis, Suite 5.1 (http://surfer. nmr.mgh.harvard.edu/). The technical details of these procedures 


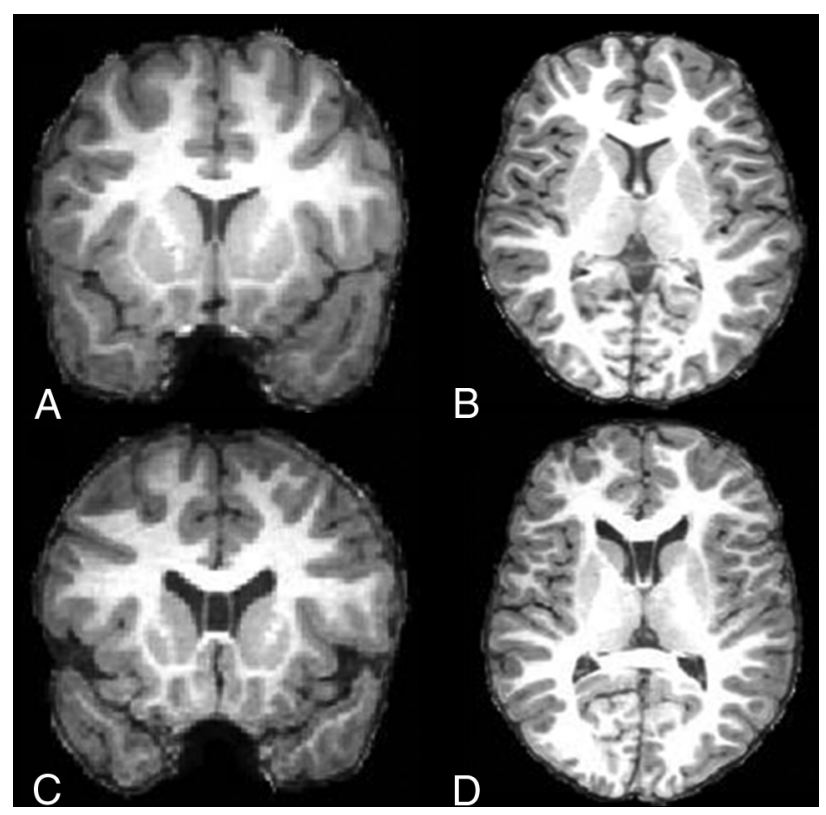

FIG 1. MR imaging of the cavum septum pellucidum. Coronal TTweighted MR image $(A)$ and axial T1-weighted MR image $(B)$ show no CSP. C, Coronal T1-weighted MR image (C) and axial T1-weighted MR image $(D)$ demonstrate an enlarged CSP.

have been described elsewhere. ${ }^{31,32}$ Briefly, this process included intensity normalization, the removal of nonbrain tissue, automated Talairach transformation into standard space, and segmentation of the cortical and subcortical white and gray matter volumetric structures. The volumes of brain regions in close vicinity to the CSP were selected for analysis. These regions included the corpus callosum, lateral ventricles, thalamus, hippocampus, amygdala, and the caudate nucleus. Volumes of global brain measures were also examined, including total brain, total gray matter, and total white matter volumes.

\section{Emotional and Behavioral Problems}

Emotional and behavioral problems were measured using the sum scores of the 99 items of the Child Behavior Checklist (CBCL). ${ }^{33}$ This questionnaire, completed by the parents when the children were approximately 6 years of age, includes behavioral, emotional, and social problems in school-aged children. The items were calculated for several syndrome scales: emotionally reactive, anxious/depressed, somatic complaints, withdrawn, attention problems, and aggressive behavior. Broadband scores of internalizing symptoms and externalizing symptoms were used.

\section{Nonverbal Intelligence}

The Generation R cohort includes children from different ethnic minorities with differences in Dutch language abilities. Therefore, nonverbal intelligence was measured using 2 subtests of the Snijders-Oomen Nonverbal Intelligence Test 2.5-7-Revised. ${ }^{34}$ Due to time constraints, we selected 2 subtests: Mosaics and categories for testing spatial insight and abstract reasoning abilities, respectively. Because the correlation between the sum of these 2 subtests and the full SON-R IQ battery is very high $(r=0.86)$, these subdomain scores can be used as nonverbal IQ scores. ${ }^{35}$ Raw subtest scores were transformed according to population- and age-specific norms with a mean value of $100 \pm 15 .{ }^{36}$ Handedness was determined using the Edinburgh Handedness Inventory. ${ }^{29}$

\section{Statistical Analyses}

Demographic differences between the no/normal-variant CSP (control group) and the enlarged CSP group were analyzed using a $\chi^{2}$ test for categoric variables (sex, ethnicity, handedness, maternal education, maternal alcohol use during pregnancy, maternal smoking behavior during pregnancy) and independent $t$ tests for continuous variables (age). Differences in brain structure volumes, nonverbal intelligence, and emotional and behavioral problems between the controls and the enlarged CSP group were tested using ANCOVAs. Covariates were added to the model if they resulted in a $>5 \%$ change in the effect estimate, including the child's age, sex, ethnicity, and maternal education. The analyses of regional brain structure volumes were also adjusted for total problem score and total brain volume. Because the control group did include a small CSP $(0-5 \mathrm{~mm})$ and the biologic relevance of a normal-sized CSP is not clear, 2 additional sensitivity analyses were performed for brain structure volumes, nonverbal intelligence, and emotional and behavior problems. First, sensitivity analyses were performed comparing the 2 extreme categories ( 0 versus $\geq 6 \mathrm{~mm}$ ), and second, an analysis was performed using a classification into 3 groups ( 0 versus $1-5$ versus $\geq 6 \mathrm{~mm}$ ). For certain analyses of brain structure volumes and emotional or behavioral scores, the length of the CSP was used as a continuous variable.

All analyses were performed using the Statistical Package for the Social Sciences, Version 21.0 (SPSS; IBM, Armonk, New York). In addition, a nonparametric analysis with CSP length as a continuous variable was performed using Statistical Analysis Software, Version 9.3 (SAS Institute, Cary, North Carolina). To correct for multiple testing, we calculated the effective number of tests on the basis of the covariance structure among the different outcomes. ${ }^{37} \mathrm{We}$ found the number of effective tests to be 5; thus, the corrected threshold for significance was $P<.01$. Data were missing on internalizing symptoms ( $10.5 \%$ missing data), externalizing symptoms (10.0\%), nonverbal IQ (8.8\%), and the covariates, maternal education $(9.5 \%)$ and the CBCL sum score $(9.5 \%)$. Missing values were estimated using a multiple imputation method with 5 imputations and 10 iterations. Finally, an additional nonresponse analysis was performed comparing the baseline characteristics of the study participants with the group of children excluded due to insufficient scan quality.

\section{RESULTS}

\section{Sample Characteristics}

Sample characteristics are presented in Table 1. Children in the control group and the enlarged CSP group did not differ in age at scanning $[t(934)=0.26, P=.79)]$, sex $\left[\chi^{2}(1)=0.03, P=.86\right]$, ethnicity $\left[\chi^{2}(2)=2.68, P=.26\right]$, handedness $\left[\chi^{2}(1)=0.001, P=\right.$ $.98]$, maternal education $\left[\chi^{2}(2)=0.93, P=.63\right]$, maternal alcohol use during pregnancy $\left[\chi^{2}(3)=1.53, P=.68\right]$, and maternal smoking behavior during pregnancy $\left[\chi^{2}(2)=0.23, P=.89\right]$.

\section{CSP}

Figure 2 shows the distribution of the anterior-to-posterior cavum lengths in the entire sample. The prevalence of a CSP in the 


\begin{tabular}{|c|c|c|c|}
\hline & $\begin{array}{c}\text { Total Group } \\
(n=936)(100 \%)\end{array}$ & $\begin{array}{c}\text { Controls } \\
(n=893)(95.4 \%)\end{array}$ & $\begin{array}{l}\text { Enlarged CSP } \\
(n=43)(4.6 \%)\end{array}$ \\
\hline \multicolumn{4}{|l|}{ Child characteristics } \\
\hline Age (mean) (SD) (yr) & $7.9(1.00)$ & $7.9(1.00)$ & $7.9(0.91)$ \\
\hline \multicolumn{4}{|l|}{$\operatorname{Sex}(\%)$} \\
\hline Girls & 45.5 & 45.6 & 44.2 \\
\hline Boys & 54.5 & 54.4 & 55.8 \\
\hline \multicolumn{4}{|l|}{ Ethnicity (\%) } \\
\hline Dutch & 68.8 & 69.0 & 65.1 \\
\hline Other Western & 6.8 & 7.1 & 2.3 \\
\hline Non-Western & 24.4 & 24.0 & 32.6 \\
\hline \multicolumn{4}{|l|}{ Handedness (\%) } \\
\hline Right & 90.5 & 90.5 & 90.7 \\
\hline Left & 9.4 & 9.4 & 9.3 \\
\hline \multicolumn{4}{|l|}{ Maternal characteristics } \\
\hline \multicolumn{4}{|c|}{ Maternal education (\%) ${ }^{\mathrm{a}}$} \\
\hline Low & 10.9 & 10.8 & 14.0 \\
\hline Medium & 29.0 & 29.0 & 27.9 \\
\hline High & 50.6 & 51.1 & 41.9 \\
\hline \multicolumn{4}{|c|}{ Alcohol during pregnancy (\%) ${ }^{\mathrm{b}}$} \\
\hline Never & 34.3 & 34.0 & 39.5 \\
\hline Stopped & 13.7 & 13.8 & 11.6 \\
\hline Occasionally & 35.7 & 35.7 & 34.9 \\
\hline Frequently & 9.2 & 9.4 & 4.7 \\
\hline \multicolumn{4}{|c|}{ Smoking during pregnancy $(\%)^{c}$} \\
\hline Never & 72.2 & 72.1 & 74.4 \\
\hline Stopped & 6.3 & 6.4 & 4.7 \\
\hline Continued & 17.9 & 17.9 & 18.6 \\
\hline
\end{tabular}

a Low indicates primary school or lower vocational education; medium, intermediate vocational education; high, higher vocational education or university. Missing data on maternal education are $9.5 \%$.

${ }^{b}$ Frequently indicates that the mother drank $\geq 1$ glass per week for at least 2 trimesters. Missing data on alcohol are $7.2 \%$. c Smoking $>10$ cigarettes per day fluctuated between $3.6 \%$ and $5.6 \%$ throughout pregnancy, with the highest percentage in the first trimester. ${ }^{41}$ Missing data on smoking are $3.5 \%$.

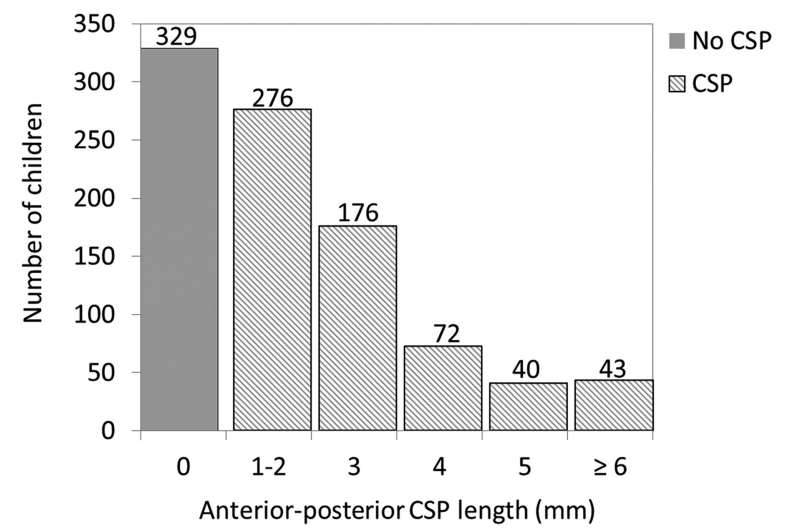

FIG 2. Distribution of no CSP, normal-variant CSP, and enlarged CSP for the whole sample $(n=936)$.

study population was $64.9 \%$, categorized into normal-variant CSP ( $60.3 \%$ of total study population) and enlarged CSP $(4.6 \%$ of total study population). The mean cavum length in the control group was $2.67 \mathrm{~mm}$; lengths ranged from 1 to $5 \mathrm{~mm}$. The mean cavum length in the enlarged CSP group was $12.56 \mathrm{~mm}$; lengths in this group ranged from 6 to $37 \mathrm{~mm}$. A histogram of CSP lengths in the enlarged CSP group is shown in On-line Fig 2.

\section{Global Brain Structures}

Table 2 shows the differences in global structure volumes between the controls and the enlarged CSP group. Children in the enlarged CSP group had larger total brain volumes $[F(1,93)=3.93, P=$
0.05, partial $\left.\eta^{2}=0.004\right]$ and larger total white matter/total brain ratio volumes $\left[F(1,93)=6.81, P=.009\right.$, partial $\eta^{2}=$ 0.007] compared with the children in the control group, adjusting for the covariates. After correcting for multiple testing, only the difference in white matter/total brain ratio volume remained. Comparing the children in the controls $(n=893)$ with the those in the enlarged CSP group $(n=43)$ or comparison of the 3 groups ( 0 versus $1-5$ versus $\geq 6$ $\mathrm{mm}$ ) showed similar results. CSP length was positively correlated with total brain volume (Spearman partial correlation, $\left.\rho_{\mathrm{s}}=0.19, P<.001\right)$ and white matter/ total brain ratio volume (Spearman partial correlation, $\left.\rho_{\mathrm{s}}=0.13, P<.001\right)$.

\section{Regional Brain Structures}

Table 3 shows the difference in volumes of specific structures between the controls and the enlarged CSP group. Children in the enlarged CSP group had larger corpus callosum volumes $\left[F(1,93)=6.79, P=.009\right.$, partial $\eta^{2}=$ 0.007], larger thalamus volumes $\left[F(1,93)=11.21, P=.001\right.$, partial $\eta^{2}=$ $0.012]$, and smaller amygdala volumes $\left[F(1,93)=4.48, P=0.04\right.$, partial $\eta^{2}=$ 0.005] compared with the children in the control group, after controlling for covariates. After we corrected for multiple testing, only differences in the corpus callosum and thalamus volumes remained. On-line Table 1 presents the results of the comparison of children in the no-CSP group $(n=329)$ with the those in the enlarged CSP group ( $\geq 6 \mathrm{~mm}$ ). Additionally, children with an enlarged CSP had smaller lateral ventricle volumes compared with children with complete absence of a cavum $[F(1,36)=8.16$, $P=.005$, partial $\left.\eta^{2}=0.022\right]$. On-line Table 2 presents the results of the comparison of the 3 groups ( 0 versus $1-5$ versus $\geq 6 \mathrm{~mm}$ ). In this analysis, the difference in amygdala volume disappeared, and the 3 groups were found to differ in caudate nucleus volume $\left[F(2,93)=5.33, P=.005\right.$, partial $\left.\eta^{2}=0.011\right]$. CSP length was positively correlated with the volume of the corpus callosum (Spearman partial correlation, $\rho_{\mathrm{s}}=0.12, P<.001$ ), thalamus (Spearman partial correlation, $\rho_{\mathrm{s}}=0.08, P=.02$ ), and caudate nucleus (Spearman partial correlation, $\rho_{\mathrm{s}}=-.10, P=.002$ ) and was negatively correlated with lateral ventricle volumes (Spearman partial correlation, $\left.\rho_{\mathrm{s}}=-.20, P<.001\right)$.

\section{Nonverbal Intelligence}

Children in the no/normal-sized CSP and the enlarged CSP groups did not differ in nonverbal IQ scores $[F(1,93)=0.05, P=$ 0.82 , partial $\left.\eta^{2}=0.000\right]$. Estimated marginal means $(\mathrm{M})$ for nonverbal IQ were $\mathrm{M}=101.63$, standard error $(\mathrm{SE})=0.46$ versus $\mathrm{M}=101.13, \mathrm{SE}=2.08$. The results of comparing the children in the no-CSP group $(n=329)$ with the enlarged CSP group ( $n=$ 
Table 2: ANCOVA for global brain structures ${ }^{a}$

\begin{tabular}{|c|c|c|c|c|c|}
\hline & \multicolumn{2}{|c|}{ Marginal Mean Volumes $\left(\mathrm{cm}^{3}\right)$ (SE) } & \multirow[b]{2}{*}{$F$} & \multirow[b]{2}{*}{ Sig. } & \multirow[b]{2}{*}{ Partial $\boldsymbol{\eta}^{2}$} \\
\hline & Controls $(n=893)$ & Enlarged CSP $(n=43)$ & & & \\
\hline TBV & $1129.09(4.095)$ & $1167.00(18.673)$ & 3.93 & .05 & 0.004 \\
\hline Total GMV/TBV & $0.63(0.001)$ & $0.63(0.003)$ & 2.14 & .14 & 0.002 \\
\hline Total WMV/TBV & $0.33(0.001)$ & $0.34(0.002)$ & 6.81 & $.009^{b}$ & 0.007 \\
\hline
\end{tabular}

Note:-TBV indicates total brain volume; GMV, gray matter volume; WMV, white matter volume; Sig., significance.

${ }^{a}$ Results of the first imputed dataset are reported; ranges of the other datasets can be found in On-line Tables 1 and 2. Covariates are age, sex, ethnicity, maternal education, and $C B C L$ sum score.

b Significant after correcting for multiple testing.

Table 3: ANCOVA for regional brain structures (control vs enlarged CSP) ${ }^{a}$

\begin{tabular}{lccccc}
\hline & \multicolumn{2}{c}{ Marginal Mean Volumes $\left(\mathbf{c m}^{\mathbf{3}}\right)(\mathrm{SE})$} & & & \\
\cline { 2 - 3 } & Controls $(\boldsymbol{n}=\mathbf{8 9 3})$ & Enlarged CSP $(\boldsymbol{n}=\mathbf{4 3})$ & $\boldsymbol{F}$ & Sig. & Partial $\boldsymbol{\eta}^{\mathbf{2}}$ \\
\hline Corpus callosum & $2.71(0.012)$ & $2.86(0.055)$ & 6.79 & $.009^{\mathrm{b}}$ & 0.007 \\
Lateral ventricles & $8.94(0.172)$ & $7.49(0.786)$ & 3.22 & .07 & 0.003 \\
Thalamus & $14.12(0.036)$ & $14.69(0.165)$ & 11.21 & $.001^{\mathrm{b}}$ & 0.012 \\
Hippocampus & $8.03(0.024)$ & $7.94(0.11)$ & 0.67 & .41 & 0.001 \\
Amygdala & $3.17(0.014)$ & $3.04(0.062)$ & 4.48 & .04 & 0.005 \\
Caudate nucleus & $8.44(0.032)$ & $8.30(0.148)$ & 0.91 & .34 & 0.001 \\
\hline
\end{tabular}

Note:-Sig. indicates significance.

a Results of the first imputed dataset are reported; ranges of the other datasets can be found in On-line Tables 1 and 2. Covariates are age, sex, ethnicity, total brain volume, maternal education, and $\mathrm{CBCL}$ sum score.

b Significant after correcting for multiple testing.

43) were also not significant. Comparing 3 groups ( 0 versus $1-5$ versus $\geq 6 \mathrm{~mm})$ did show a difference in nonverbal IQ scores $\left[F(1,93)=3.37, P=0.04\right.$, partial $\left.\eta^{2}=0.007\right]$. Estimated marginal means for the 3 groups were $\mathrm{M}=100.08, \mathrm{SE}=0.75$ versus $\mathrm{M}=102.53, \mathrm{SE}=0.57$ versus $\mathrm{M}=101.14, \mathrm{SE}=2.07$; however, this finding did not survive correction for multiple testing. A nonparametric test with CSP length as a continuous variable did not show a correlation between CSP length and nonverbal IQ scores.

\section{Emotional or Behavioral Problems}

Children in the control group and the enlarged CSP group did not differ in emotional $\left[F(1,93)=2.35, P=0.13\right.$, partial $\left.\eta^{2}=0.003\right]$ or behavioral $\left[F(1,93)=0.35, P=0.55\right.$, partial $\left.\eta^{2}=0.000\right]$ problem scores. Estimated marginal means for emotional scores were $\mathrm{M}=2.48, \mathrm{SE}=0.04$ versus $\mathrm{M}=2.18, \mathrm{SE}=0.19$. Estimated marginal means for behavioral scores were $\mathrm{M}=2.80, \mathrm{SE}=0.04$ versus $\mathrm{M}=2.93, \mathrm{SE}=0.20$. Mean scores are reported as squareroot-transformed scores. Comparing the children in the no-CSP group ( $n=329)$ with those in the enlarged CSP group $(n=43)$ or comparing 3 groups ( $0 \mathrm{~mm} 1-5$ versus $\geq 6 \mathrm{~mm}$ ) did not change the results. A Spearman correlation coefficient test with CSP length as a continuous variable also did not show a correlation between CSP length and emotional or behavioral scores.

\section{Participant versus Excluded Analysis}

Of all 1070 scans, 134 scans (12.5\%) were of insufficient quality and were excluded from the analyses. Children whose scans were excluded did not differ from the current study sample $(n=936)$ in age at the time of scanning $[t(1068)=-0.81, P=.42]$, sex $\left[\chi^{2}(1)=3.18, P=.07\right]$, ethnicity $\left[\chi^{2}(2)=3.85, P=.15\right]$, handedness $\left[\chi^{2}(1)=0.43, P=.51\right]$, nonverbal IQ $[t(980)=-0.59$, $P=.56]$, maternal education $\left[\chi^{2}(2)=3.83, P=.15\right]$, maternal alcohol use during pregnancy $\left[\chi^{2}(3)=1.12, P=.77\right]$, and maternal smoking behavior during pregnancy $\left[\chi^{2}(2)=5.64\right.$, $P=.06]$. However, children excluded from the analyses had higher CBCL sum scores than the included children $[t(970)=2.53, P=.01]$.

\section{DISCUSSION}

To further understand the brain structural correlates associated with an enlarged CSP, we evaluated the relationship between the CSP and the volume of global and regional brain structures. Children with enlarged CSPs were found to have larger total white matter/ total brain volume ratios and corpus callosum and thalamus volumes. Similar to studies in patients with schizophrenia spectrum disorder, ${ }^{12}$ amygdala volumes were smaller in subjects with enlarged CSPs. However, this result did not remain significant after correction for multiple testing. In addition, children with enlarged CSPs had smaller lateral ventricle volumes compared with children with a total absence of a cavum. CSP length was positively correlated with total brain volume; white matter/total brain ratio; and corpus callosum, thalamus, and caudate nucleus volumes. CSP length was negatively correlated with lateral ventricle volumes.

It has been postulated that the postnatal closure of the CSP is a result of growth of surrounding brain structures, exerting pressure on the 2 leaflets of the septum pellucidum and thereby facilitating fusion. ${ }^{2,3}$ Brain development in this early postnatal period has not been extensively studied, but a recent study on infant brain development in the first 3 months after birth ${ }^{38}$ presents growth rates for several ROIs of the current study. The lateral ventricles were found to grow at the highest rate, increasing around $78 \%$ in the first 90 days after birth. As hypothesized, the rapid growth of the lateral ventricles in these first months after birth could induce closure of the cavum by exerting lateral pressure on both sides of the septal leaves. We speculated that smaller growth rates in this period could cause failure of CSP closure. If these early growth rates are decisive for structure volumes at a later age, our results support this hypothesis because the lateral ventricles were smaller in children with the presence of a CSP compared with those with total absence of a cavum. Previous studies have reported an association between an enlarged CSP and syndromes including cognitive impairment such as fetal alcohol syndrome and Apert syndrome. ${ }^{25,26}$

Mechanical factors that potentially play a role in the closure of the CSP in the general pediatric population could also extend to these clinical conditions. In these syndromes, there is an obvious change in brain volume and/or head size, which could cause major changes in the exerting pressure on the septal leaves, leading to a failure of CSP closure. The enlarged CSP would rather be a consequence of the anatomic and structural abnormalities in these syndromes than a marker of cognitive function itself. In addition, the larger total amount of white matter (larger total white matter/total brain volumes ratios) in the enlarged CSP group could also contribute to a change in mechanical factors that 
cause the lateral ventricles to grow less rapidly in the early postnatal period. This, in turn, could modify the exerting lateral pressure on both sides of the septal leaves and alter the possible closure mechanisms of the septal leaves.

In addition, other regional brain structures were also found to be larger in children with a persistent CSP. For example, the corpus callosum is a structure that directly surrounds the CSP but was found to be larger in children with an enlarged CSP. We speculated that the exertion of lateral pressure, like the pressure of growing lateral ventricles, is more effective in facilitating the postnatal fusing process of the septum leaves if the corpus callosum is smaller. Thus, under the rubric of a mechanical closure hypothesis of the CSP, larger brain structures would require greater distributed pressure along the structure to close the septum. However, because we do not have MR imaging data available during the early postnatal period, it is not possible to draw conclusions concerning the timing and longitudinal relationship with neighboring structures related to the postnatal closure of the CSP. It is likely that multiple-yet-unknown factors play a role in this process.

Furthermore, it would be interesting to search for genetic factors that play a role in the closure of the CSP. Because the Generation R Study is currently starting to prospectively scan the parents of a subgroup of children scanned in this study, assessment of the presence and size of a CSP in the parents could be of great value to demonstrate the influence of genetics. This may well be a focus of further studies.

The prevalence of an enlarged CSP in our population-based sample of school-aged children is $4.6 \%$. This falls within the range described in prior literature in adult populations. ${ }^{2,3,5-16}$ While earlier research tended to focus on psychiatric populations, the prevalence in healthy control groups in these studies varied substantially from $0 \%$ to $14.7 \%$. Because many of these studies had small sample sizes and control groups are not always reflective of recruitment from the general population, we believe that our study provides more accurate rates of enlarged CSPs in the general pediatric population. However, we are unaware of studies assessing changes with time in the size or presence of the CSP; thus, longitudinal studies are necessary to address this question.

An enlarged CSP is considered a potential marker for neurodevelopmental abnormalities. However, in contrast to earlier studies, ${ }^{11,15,19}$ we did not find a relationship between an enlarged CSP and nonverbal intelligence. We also did not find a relationship between emotional or behavioral problems and an enlarged CSP. While we found no evidence for behavioral correlates of an enlarged CSP in this population-based sample of school-aged children, some neuropsychiatric disorders that show a relationship with an enlarged CSP have a typical age of onset in late adolescence and early adulthood. For example, schizophrenia spectrum disorders and bipolar disorders generally present with the first symptoms between 17 and 25 years of age. ${ }^{7,21}$ Thus, it is possible that the relationship between an enlarged CSP and psychopathology will emerge later, parallel to the emergence of psychiatric symptoms. The small, nonsignificant, volumetric differences of certain brain structures found in this study could theoretically indicate some structural changes in brain regions that might form the basis for these diseases.
There are some limitations in the study protocol. Only 1 rater evaluated the MR imaging studies and assessed the presence and size of the CSP. However, the rater was specifically trained to evaluate the CSP and performed all the measurements in a standardized manner. Furthermore, 1 exclusion criterion to undergo MR imaging examination in the Generation $\mathrm{R}$ Study design is a history of moderate-to-severe head injuries with loss of consciousness. In previous literature, a possible relationship between an enlarged CSP and traumatic brain injury has been reported in adults as well as in children. ${ }^{39,40}$ Therefore, exclusion of children with previous moderate-to-severe brain injury potentially resulted in selection bias. In addition, missing values on internalizing and externalizing symptoms, nonverbal IQ, and certain covariates are a potential limitation of the study design, but we applied multiple imputation methods to reduce the potential bias introduced as a result of missing data to a minimum.

The strengths of the current study are the standardized MR imaging measurements obtained in a large population-based sample of 1070 children of different ethnicities and backgrounds. The study contains an extensive data collection with a broad range of physiologic and environmental measures. Therefore, it includes valuable data representative of the pediatric population in general.

\section{CONCLUSIONS}

The CSP is a structural brain variation without cognitive or behavioral implications in this population-based sample of schoolaged children. However, we did find a relationship between CSP and global and regional volumetric brain measures, but the clinical relevance of this relationship is as yet uncertain.

Disclosures: Marjolein H.G. Dremmen—RELATED: Grant: the Netherlands Organization for Health Research and Development*; UNRELATED: Employment: Pediatric Radiologist at Erasmus Medical Center, Rotterdam. Roos H. Bouhuis-RELATED: Grant: the Netherlands Organization for Health Research and Development. * Hanan El Marroun—RELATED: Grant: European Union, Comments: The Horizon 2020 research and innovation program (grant agreement No.633595 DynaHEALTH and No.733206 LifeCycle) of the European Union. * Frank C. Verhulst—UNRELATED: Royalties: distributor of the Dutch translations of the Achenbach System of Empirically Based Assessment, from which I receive remuneration. Tonya White-RELATED: Grant: the Netherlands Organization for Health Research and Development.* *Money paid to the institution.

\section{REFERENCES}

1. Sarwar M. The septum pellucidum: normal and abnormal. AJNR Am J Neuroradiol 1989;10:989-1005 Medline

2. Dickey CC, McCarley RW, Xu ML, et al. MRI abnormalities of the hippocampus and cavum septi pellucidi in females with schizotypal personality disorder. Schizophr Res 2007;89:49-58 CrossRef Medline

3. Choi JS, Kang DH, Park JY, et al. Cavum septum pellucidum in subjects at ultra-high risk for psychosis: compared with first-degree relatives of patients with schizophrenia and healthy volunteers. Prog Neuropsychopharmacol Biol Psychiatry 2008;32:1326-30 CrossRef Medline

4. Shunk H. Congenital dilatations of the septi pellucidum. Radiology 1963;81:610-18 CrossRef Medline

5. Nopoulos PC, Giedd JN, Andreasen NC, et al. Frequency and severity of enlarged cavum septi pellucidi in childhood-onset schizophrenia. Am J Psychiatry 1998;155:1074-79 CrossRef Medline

6. Hagino H, Suzuki M, Kurokawa K, et al. Magnetic resonance imaging study of the cavum septi pellucidi in patients with schizophrenia. Am J Psychiatry 2001;158:1717-19 CrossRef Medline

7. Rajarethinam R, Miedler J, DeQuardo J, et al. Prevalence of cavum 
septum pellucidum in schizophrenia studied with MRI. Schizophr Res 2001;48:201-05 CrossRef Medline

8. Crippa JA, Uchida R, Busatto GF, et al. The size and prevalence of the cavum septum pellucidum are normal in subjects with panic disorder. Braz J Med Biol Res 2004;37:371-74 CrossRef Medline

9. de Souza Crippa JA, Zuardi AW, Busatto GF, et al. Cavum septum pellucidum and adhesio interthalamica in schizophrenia: an MRI study. Eur Psychiatry 2006;21:291-99 CrossRef Medline

10. Flashman LA, Roth RM, Pixley HS, et al. Cavum septum pellucidum in schizophrenia: clinical and neuropsychological correlates. Psychiatry Res 2007;154:147-55 CrossRef Medline

11. Kim MJ, Lyoo IK, Dager SR, et al. The occurrence of cavum septi pellucidi enlargement is increased in bipolar disorder patients. $B i$ polar Disord 2007;9:274-80 CrossRef Medline

12. Takahashi T, Suzuki M, Hagino H, et al. Prevalence of large cavum septi pellucidi and its relation to the medial temporal lobe structures in schizophrenia spectrum. Prog Neuropsychopharmacol Biol Psychiatry 2007;31:1235-41 CrossRef Medline

13. Takahashi T, Yücel M, Lorenzetti V, et al. Midline brain structures in patients with current and remitted major depression. Prog Neuropsychopharmacol Biol Psychiatry 2009;33:1058-63 CrossRef Medline

14. Chon MW, Choi JS, Kang DH, et al. MRI study of the cavum septum pellucidum in obsessive-compulsive disorder. Eur Arch Psychiatry Clin Neurosci 2010;260:337-43 CrossRef Medline

15. Raine A, Lee L, Yang Y, et al. Neurodevelopmental marker for limbic maldevelopment in antisocial personality disorder and psychopathy. Br J Psychiatry 2010;197:186-92 CrossRef Medline

16. Hwang J, Kim JE, Kaufman MJ, et al. Enlarged cavum septum pellucidum as a neurodevelopmental marker in adolescent-onset opiate dependence. PLoS One 2013;8:e78590 CrossRef Medline

17. Galarza $M$, Merlo AB, Ingratta $A$, et al. Cavum septum pellucidum and its increased prevalence in schizophrenia: a neuroembryological classification. J Neuropsychiatry Clin Neurosci 2004;16:41-46 CrossRef Medline

18. Kasai K, McCarley RW, Salisbury DF, et al. Cavum septi pellucidi in first-episode schizophrenia and first-episode affective psychosis: an MRI study. Schizophr Res 2004;71:65-76 CrossRef Medline

19. White SF, Brislin S, Sinclair S, et al. The relationship between large cavum septum pellucidum and antisocial behavior, callous-unemotional traits and psychopathy in adolescents. J Child Psychol Psychiatry 2013;54:575-81 CrossRef Medline

20. Rajarethinam R, Sohi J, Arfken C, et al. No difference in the prevalence of cavum septum pellucidum (CSP) between first-episode schizophrenia patients, offspring of schizophrenia patients and healthy controls. Schizophr Res 2008;103:22-25 CrossRef Medline

21. Takahashi T, Malhi GS, Wood SJ, et al. Midline brain abnormalities in established bipolar affective disorder. J Affect Disord 2010;122: 301-05 CrossRef Medline

22. Nopoulos P, Berg S, Castellenos FX, et al. Developmental brain anomalies in children with attention-deficit hyperactivity disorder. J Child Neurol 2000;15:102-08 CrossRef Medline

23. Nopoulos P, Krie A, Andreasen NC. Enlarged cavum septi pellucidi in patients with schizophrenia: clinical and cognitive correlates. J Neuropsychiatry Clin Neurosci 2000;12:344-49 CrossRef Medline

24. Bodensteiner JB, Schaefer GB, Craft JM. Cavum septi pellucidi and cavum vergae in normal and developmentally delayed populations. J Child Neurol 1998;13:120-21 CrossRef Medline

25. Swayze VW 2nd, Johnson VP, Hansen JW, et al. Magnetic resonance imaging of brain anomalies in fetal alcohol syndrome. Pediatrics 1997;99:232-40 CrossRef Medline

26. Renier D, Arnaud E, Cinalli G, et al. Prognosis for mental function in Apert's syndrome. J Neurosurg 1996;85:66-72 Medline

27. Jaddoe VW, Mackenbach JP, Moll HA, et al. The Generation R Study: design and cohort profile. Eur J Epidemiol 2006;21:475-84 CrossRef Medline

28. White T, El Marroun H, Nijs I, et al. Pediatric population-based neuroimaging and the Generation R Study: the intersection of developmental neuroscience and epidemiology. Eur J Epidemiol. 2013; 28:99-111 CrossRef Medline

29. White T, Muetzel RL, El Marroun H, et al. Paediatric population neuroimaging and the Generation R Study: the second wave. Eur J Epidemiol 2018;33:99-125 CrossRef Medline

30. Muetzel RL, Blanken LME, Thijssen S, et al. Variability in ICA-derived resting-state networks in 6-to-10 year-old children. Hum Brain Mapp 2016;37:4286-4300 CrossRef Medline

31. White T, Jansen PR, Muetzel RL, et al. Automated quality assessment of structural magnetic resonance images in children: comparison with visual inspection and surface-based reconstruction. Hum Brain Mapp 2018;39:1218-31 CrossRef Medline

32. Fischl B, Salat DH, Busa E, et al. Whole brain segmentation: automated labeling of neuroanatomical structures in the human brain. Neuron 2002;33:341-55 CrossRef Medline

33. Achenbach TM, Rescorla LA. Manual for the ASEBA Preschool Forms and Profiles. Burlington, VT: University of Vermont, Research Center for Children, Youth, \& Families; 2000

34. Basten $\mathrm{M}$, van der Ende J, Tiemeier $\mathrm{H}$, et al. Nonverbal intelligence in young children with dysregulation: the Generation R Study. Eur Child Adolesc Psychiatry 2014;23:1061-70 CrossRef Medline

35. Moore C, O'Keefe S, Lawhorn D, et al, et al. Concurrent validity of the Snijders-Oomen Nonverbal Intelligence Test 2 1/2-7-Revised with the Wechsler Preschool and Primary Scale of IntelligenceRevised. Psychological Reports 1998;82:619-25 CrossRef

36. Snijders JH, Snijders-Oomen AW, Tellegen PJ, et al. SON-R 21/2-7: Snijders-Oomen Niet-Verbale Intelligentietest-Handleiding en $\mathrm{Ve}$ rantwoording. Amsterdam: Boom Testuitgevers; 2005

37. Galwey NW. A new measure of the effective number of tests, a practical tool for comparing families of non-independent significance tests. Genet Epidemiol 2009;33:559-68 CrossRef Medline

38. Holland D, Chang L, Ernst TM, et al. Structural growth trajectories and rates of change in the first 3 months of infant brain development. JAMA Neurol 2014;71:1266-74 CrossRef Medline

39. Lee JK, Wu J, Banks S, et al. Prevalence of traumatic findings on routine MRI in a large cohort of professional fighters. AJNR Am J Neuroradiol 2017;38:1303-10 CrossRef Medline

40. Silk T, Beare R, Crossley L, et al. Cavum septum pellucidum in pediatric traumatic brain injury. Psychiatry Res 2013;213:186-92 CrossRef Medline

41. El Marroun H, White TJ, van der Knaap NJ, et al. Prenatal exposure to selective serotonin reuptake inhibitors and social responsiveness symptoms of autism: population-based study of young children. Br J Psychiatry 2014;205:95-102 CrossRef Medline 